\title{
Profit raising entry effects in network industries with Corporate Social Responsibility
}

\author{
Luciano Fanti ${ }^{1} \cdot$ Domenico Buccella $^{2 *}$ \\ ${ }^{1}$ Department of Economics and Management, University of Pisa, Pisa, Italy \\ ${ }^{2}$ Department of Economics, Kozminski University, Warsaw, Poland
}

\begin{abstract}
This note investigates the possibility of profit raising entry in network industries where firms follow Corporate Social Responsibility (CSR) behaviours, showing the interaction between the network and CSR features. In particular, for high levels of the network effect, an incumbent's profits raising entry effect occurs. The latter result is at odds with the conventional wisdom and shows another channel the preceding literature has so far not explored for the possibility of a profit raising entry.
\end{abstract}

Keywords: CSR; duopoly; profitability; profit raising effect

JEL Classification Codes: L13, M13

\section{Introduction}

The traditional view of market competition suggests that entry of a firm reduces the profits of the incumbent firms through increased competition in the marketplace; thus, the incumbent firms want to deter entry. However, this traditional view has been recently challenged by numerous papers which have argued for the possibility of a profit raising entry.

Such papers have stressed different alternative reasons for challenging the traditional view. Tyagi (1999), Naylor (2002a,b) and Mukherjee et al. (2009) argued for a profit raising entry effect of vertical relationships. Pal and Sarkar (2001) and Mukherjee and Zhao (2009) show that a profit raising entry may be due to a Stackelberg competition with asymmetric cost firms. Coughlan and Soberman (2005), Chen and Riordan (2007) and Ishibashi and Matsushima

\footnotetext{
* Corresponding author. E-mail: buccella@kozminski.edu.pl.

Citation: Fanti, L. and Buccella, D. (2017) Profit raising entry effects in network industries with Corporate Social Responsibility, Economics and Business Letters, 6(3), 59-68.
}

Oviedo University Press 
(2009) show that the presence of differentiated products may be responsible for a profit raising entry effect. The presence of some weak competitors as a trigger for deterring entry of some stronger firms is supported by Ashiya (2000). Ishida et al. (2011) show that entry of a firm with a less efficient initial production technology may increase the R\&D investment and the profit of an incumbent firm with a more efficient initial production technology.

In this paper we focus on an industry with network externalities in consumption and in which firms adopt Corporate Social Responsibility (CSR) rules. According to Garriga and Melè (2004), the most relevant CSR approaches concentrate on one of the following aspects of social reality: economics, politics, social integration and ethics. More in detail, CSR can be defined as a "company's verifiable commitment to operating in an economically, socially and environmentally sustainable manner that is transparent and increasingly satisfying to its stakeholders", and CSR activities may (broadly) range from, for example, the adoption of codes of conduct and customer relationship management such as consumer friendliness (economic aspects) to environmental performance, labour practice indicators, standards for suppliers and philanthropy (social aspects) (Katsoulakos et al., 2004). We concentrate on one of the economic aspects of the CSR adoption, i.e. consumer friendliness. In this paper, as in the most part of the literature assuming an exogenous weight on the consumer surplus in the objective function of the firm, it is implicitly postulated a "stakeholder" view of the firm - see Freeman (1984) - which states that managers aim to satisfy a variety of stakeholders (e.g., suppliers, consumers, workers, local communities, organizations of activists) so departing from the objective of the pure profits and influencing firm outcomes ${ }^{1}$.

The adoption of CSR activities in network industries, for instance, in the big companies in electronic and telecommunications, is rather widespread. In fact, the Reputation Institute global CSR survey reports that, among the world's top ten companies with the best CSR reputations, prominent companies operate in network industries: Google ranks first, Microsoft 4th, Apple 7th and Intel 8th (Reputation Institute, 2015). Therefore, the research question is whether and how the features of this industry, namely the intensity of the network effect and the level of engagement in social activities, may lead to a profitable entry.

In the recent years the debate on firms' social responsibility has been raised more frequently in the political agenda (see e.g. European Commision, 2001) as well as in the academic literature (e.g. Baron, 2001, 2009; Jensen, 2001; Frank, 2003; Goering, 2007, 2008; Lambertini and Tampieri, 2010; Benabou and Tirole, 2010; Planer-Friedrich and Sahm, 2016). On the other hand, network industries are gaining momentum in contemporary economics ${ }^{2}$. Moreover, network effects can be relevant and, as a recent literature has shown, several established results of the industrial organization, obtained under the assumption of standard goods, may be reshaped. For instance, Hoernig (2012), Battacharjee and Pal (2014), and Chirco and Scrimitore (2013) have shown that network externalities alter the traditional results of the oligopoly managerial delegation literature.

Nevertheless, the analysis of CSR in network industries is rather scant. As KPMG (2013) reports, CSR activities are currently a worldwide dominant business practice. In particular, the

\footnotetext{
${ }^{1}$ In the words of Mc Williams et al. (2005, p.5), "according to this view, it is not sufficient for managers to focus exclusively on the needs of stockholders, or the owners the corporation. Stakeholder theory implies that it can be beneficial for the firm to engage in certain CSR activities that non-financial stakeholders perceive to be important, because, absent this, these groups might withdraw their support for the firm". For the sake of precision, the firm's objective function with exogenous weight on consumer surplus may be also justified postulating a Kantian moral imperative for managers to "do the right thing," independently of the effects on firm's profits, e.g. Donaldson and Preston (1995).

${ }^{2}$ The widespread diffusion of mobile devices such as smartphones and tablets, and the undeniable use of computers and related software in all social and economic activities, are, perhaps, the most clear and tangible examples of the growing relevance of those industries in everyday life.
} 
telecommunications \& media sectors have experienced a notable development pace in recent years, increasing their CSR reporting from 47 percent in 2008 to 75 percent in 2013, while electronics \& computers from 58 percent to 78 percent, two of the highest levels amid the surveyed industries. The current paper aims to fill this gap.

In particular, the key result of this note is that under precise assumptions below discussed, in the absence of barriers ${ }^{3}$, when the network effects are very intense the conventional wisdom about the reduction of incumbent's profits after entry is reversed: the duopoly profits are larger than the monopoly profit and the incumbent may welcome entry. This result seems to suggest that, when network industries with CSR behaviours are involved, policy makers have to pay much attention to the interactions between the specific features of these industries, i.e. levels of firms' social concerns and network effect intensity, in shaping antitrust and competition policies.

The rest of this paper is structured as follows. Section 2 introduces the monopoly and duopoly models with network goods and exogenous CSR rules, and discuss the analysis of profit raising entry in this context. The last section concludes outlining the future directions of research.

\section{The model}

We first develop the monopoly model in the network industry. Through the paper we assume that the simple network effect mechanism at work is the one described in the seminal paper of Katz and Shapiro (1985), i.e. the surplus a firm's client obtains directly grows with the number of other clients of this firm ${ }^{4}$. Following Bhattacharjee and Pal (2013), Fanti and Buccella (2016, 2017a), and Buccella and Fanti (2016), the inverse demand function is

$$
p=a-q+n y,
$$

where $p$ is the price of goods, $q$ denotes the quantity of the goods produced and $y$ denotes the consumers' expectation about the monopolist's equilibrium production ${ }^{5}$. The parameter $n \in[0,1)$ represents the strength of the network effects: the higher the value of the parameter is, the stronger the externalities are.

To focus on the impact of the adoption of CSR rules in this industry, we consider that the firm's marginal cost is zero. Given (1), the monopolist's profit function is

$$
\pi=(a-q+n y) q .
$$

Following the recent established literature (e.g. Goering 2007, 2008; Lambertini and Tampieri, 2010; Fanti and Buccella, 2017b,c) our model assumes that all the social concerns can be

\footnotetext{
${ }^{3}$ For a discussion of the distinction between "innocent" and strategic barriers see Church and Ware (1999), McAfee et al. (2003, 2004) and Buccella and Fanti (2016).

${ }^{4}$ In particular it is assumed that consumers - when deciding to buy - take into account their expectations on which will be the size of network, because they buy when the actual network sizes are not known. The main features of the mechanism behind the network effect in the consumer's demand function is clearly described by Katz and Shapiro (1985, p.426): "First, consumers form expectations about the size of the network with which each firm is associated. Second, the firms play an output game, taking consumers expectations as given. [...] Consumers then make their purchase decisions by comparing their reservation prices (based on expected network sizes) with the prices set by the $\mathrm{n}$ firms, $i=1, \ldots, n$. We do not explicitly model the process through which consumers' expectations are formed. We will, however, impose the requirement that in equilibrium consumers' expectations are fulfilled". ${ }^{5}$ Note that this work strictly follows the assumptions of Katz and Shapiro (1985). Nonetheless, as those authors remark, in some contexts, firms may be able to commit strongly to an output level before consumers make their purchase decisions (only the equilibrium production levels are credible announcements). In such cases, the effect of the monopolist's production decisions without expectations may lead to different equilibrium outcomes. The analysis of this possibility is left for further research.
} 
interpreted as "consumer friendly activities". As a consequence, the characteristic of a CSR firm is to be responsive to consumers. One may consider the inclusion of a fraction $k$ of the consumer surplus as the firm's "social concern" or care for consumer outcomes in the market. As a consequence, the CSR firm's objective function may simply be specified as a parameterised combination of profits $(\pi)$ and consumer surplus $(C S)^{6}$. Thus, the CSR objective function $\left(W_{i}\right)$ is:

$$
W=\pi+k C S=(a-q+n y) q+k \frac{\left(q^{2}-n y^{2}\right)}{2},
$$

where $k \in[0,1)$ denotes the weight that the CSR firm assigns to consumer surplus ${ }^{7,8}$.

The analysis is carried out as usual through the maximisation of (3) with respect to the quantity. Maximisation of (3) leads to

$$
q(y)=\frac{a+n y}{2-k} .
$$

At this stage, consumers fulfil their expectations about the monopolist's output level at equilibrium, i.e. $y=q$. Therefore, from (4), after imposing the "rational expectations" condition, we obtain that the actual output in equilibrium is

$$
q^{M}=\frac{a}{2-n-k} .
$$

After substitution of (5) into (2), the monopoly profits are

$$
\pi^{M}=\frac{a^{2}(1-k)}{(2-n-k)^{2}} .
$$

Consider now the case of duopoly. We define firm 1 as the incumbent and firm 2 the entrant. In duopoly, the (inverse) demand function becomes

$$
p=a-q_{i}-q_{j}+n\left(y_{i}+y_{j}\right),
$$

where $q_{i}$ and $q_{j}$ are the firms' output levels for $i, j=1,2$ and $i \neq j$. Thus, the firms' CSR objective function $(W)$ are:

\footnotetext{
${ }^{6}$ Thus, stakeholders "influence" the firm's objective, and once involved in the firm's governance, fix the "social engagement" level. Consequently, the present model assumes that the private owners of the CSR firm takes as exogenously given the level of "social concern", $k$, by the stakeholders' "customary toughness" integrated in the firm's objective function. This is coherent with the findings of the empirical study of Spitzeck and Hansen (2010). According to those authors, the engagement mechanism of the stakeholders is usually circumscribed to "dialogue \& issues" advisory. Furthermore, given that firms compete for the same clients within a sector, it can be fairly assumed that the CSR level stakeholders demand is identical for both companies.

${ }^{7}$ The consumer surplus' value is obtained from the maximisation of the utility function of the representative consumer minus the expenditure for the goods consumed, i.e. $C S=U-p q$ (see, e.g. Nakamura, 2013), where $U=a q$ $\left.-(1 / 2) q^{2}+n\left(y q-(1 / 2) y^{2}\right)\right)$, which is an adaptation to the monopoly case of the utility function in Battacharjee and Pal (2014). When rational expectations realize, i.e. $y=q$, the expression of the consumer surplus collapses to $C S$ $=(1-n)\left(q^{2} / 2\right)$, both with the current and the standard definition (the value of the area delimited by the demand function and the price consumers pay).

${ }^{8}$ Goering $(2007,2008)$ attributes this objective function also to the Non-profit organizations (NPO) which compete in commercial markets, for instance in sectors including University bookstores (Schiff and Weisbrod, 1991), water utility, rail track maintenance company, private air-traffic control organization (Bennett et al., 2003) and even in the high-tech markets (Benz, 2005). Therefore, commercial NPOs selling their output and services, which provide them revenue, may be considered CSR firms.
} 


$$
W_{i}=\pi_{i}+k C S=\left[a-q_{i}-q_{j}+n\left(y_{i}+y_{j}\right)\right] q_{i}+k\left[\frac{\left(q_{i}+q_{j}\right)^{2}-n\left(y_{i}+y_{j}\right)^{2}}{2}\right] i, j=1,2, i \neq j .
$$

Given (8), the firms' maximization problem and the solution of the first-order conditions' system, followed by the imposition of the "rational expectations" condition $y_{i}=q_{i}, i=1,2$, leads to the firms' output decision, where the upper script $D$ stands for "duopoly":

$$
q^{D}=\frac{a}{3-2(n+k)} .
$$

Substituting (9) into the firms' profit functions, the duopoly profits in equilibrium are

$$
\pi^{D}=\frac{a^{2}(1-2 k)}{[3-2(n+k)]^{2}} .
$$

Note that the satisfaction of the non-negativity constraints on profits requires ultimately that $k \leq 1 / 2$ : that is, the firm's interest for the consumers' welfare has not to be too high. This inequality also holds true for the rest of the paper.

Let us briefly discuss the results. Defining

$$
\Delta=\pi^{M}-\pi^{D}=-\frac{a^{2}\left(2 k^{3}-4 k^{2} n+2 k n^{2}-7 k^{2}-10 k n-3 n^{2}+9 k+8 n-5\right)}{[3-2(n+k)]^{2}(2-n-k)^{2}},
$$

the following result holds:

Result 1: For $n \geq n^{\mathrm{P}} \equiv \frac{4-5 k+2 k^{2}-\sqrt{2 k^{2}-3 k+1}}{3-2 k}$, where the upper script $\mathrm{P}$ stands for "profit raising", $\Delta \leq 0$ : therefore, an incumbent's profits raising entry effect occurs, which is relatively more intense for intermediate levels of the CSR parameter ${ }^{9}$.

A graphical analysis exhaustively shows the content of Result 1. Figure 1 shows the behaviour of the profit differential with an increasing $n$ for different degrees of the "social engagement". It is easy to see that an increasing $k$ plays a not univocal role. In fact, if on one hand for lower levels of $k$ the profit differential is restrained for a wide range of the network effect, on the other hand the profit raising effect appears only for very high levels of $n$. As $k$ increases, first the value of $\Delta$ increases as well; however, then it sharply falls allowing for an early emergence of the profit raising effect. Finally, when the CSR level approaches its value limit of $k=$ $0.5, \Delta$ tends to increase further and then more rapidly fall, nonetheless requiring a more intense level of $n$ such to make $\Delta \leq 0$. An analytical inspection reveals that $\partial n^{\mathrm{P}} / \partial k \geq 0$ for $k \geq 0.35$ implying that the lowest level at which the profit raising effect arises is $n=0.89$. Figure 2 shows the area of the combination of the two parameters of interest in which the profit raising entry effect emerges.

To sum up, Result 1 shows that the interactions of CSR features and network externalities imply that when the network effects are very high the conventional view about the entry effects is reversed: duopoly profits can be larger than monopoly profits for the incumbent. The rationale for these results is as follows. On one hand, network externalities induce firms to expand output; on the other hand, those effects push a downward pressure on prices. However, an indepth analytical inspection reveals the following.

\footnotetext{
${ }^{9}$ Notice that in the absence either of any CSR activity (i.e. $k=0$ ) or of any network effect (i.e. $n=0$ ) the profit raising entry effect can never occur. Therefore, the key ingredient for the appearance of such an effect is the interaction between the network effects and the firms' social concern.
} 
Figure 1. Plot of profit differential $\Delta$ with a varying network effect parameter for five values of the CSR parameter and $a=1$

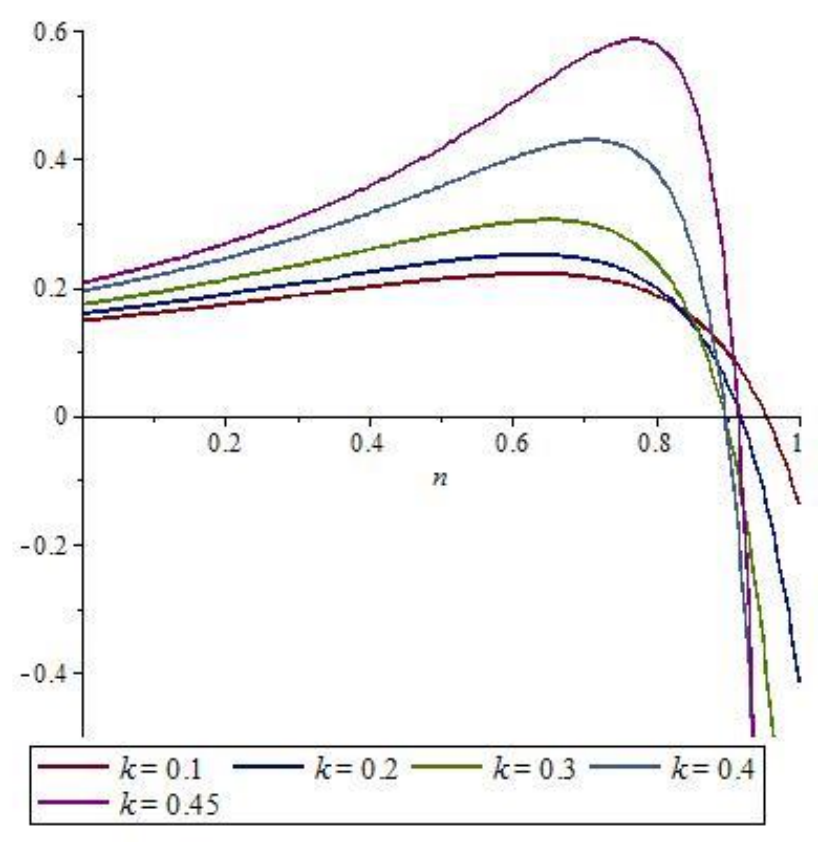

Figure 2. Plot of the (feasible) region in which the profit raising entry effect occurs (i.e. $\Delta<0$ ), in the $(k, n)$-parametric plane for $a=1$

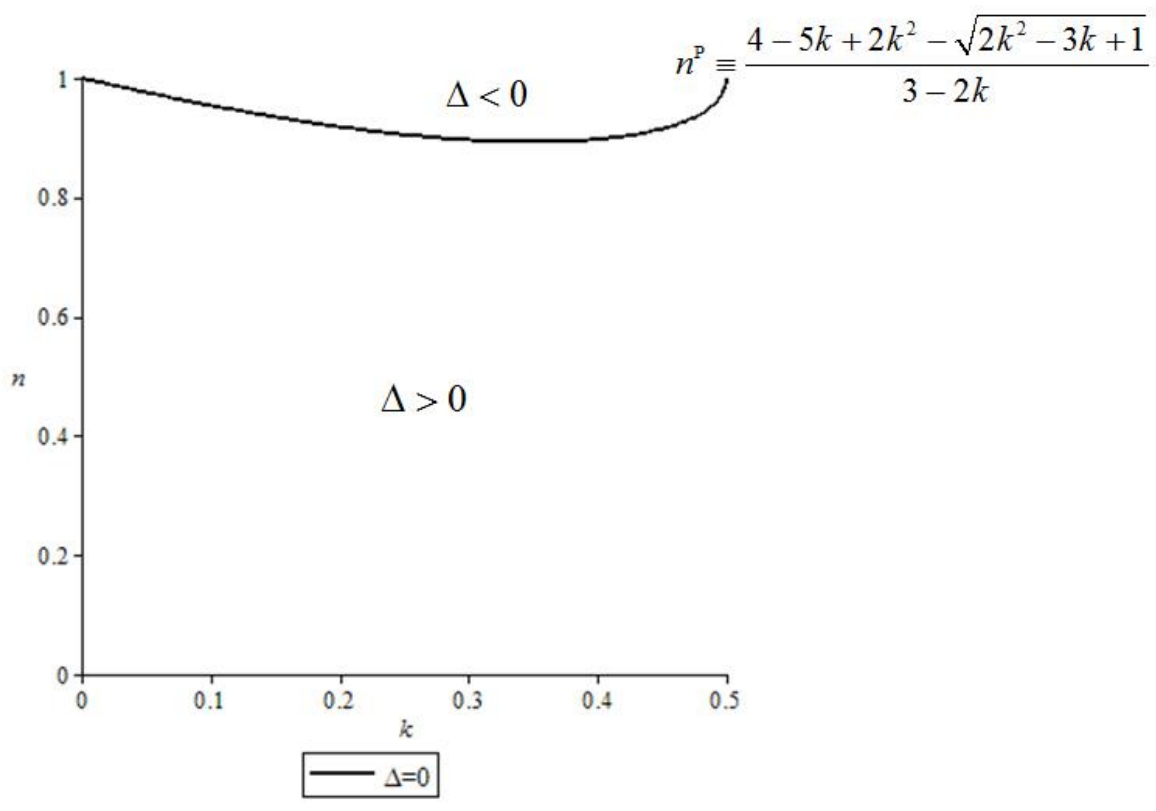

Lemma 1: In the relevant range of $k$, while the price under monopoly is always higher than under duopoly, the quantity may become lower if $n$ is sufficiently high.

Proof: $p^{M}>p^{D} ; q^{M} \underset{<}{<} q^{D} \Leftrightarrow n \frac{<}{>} 1-k$.

Therefore, if the price under monopoly is always higher than that under duopoly, Lemma 1 shows that it is the quantity effect that drives duopoly profits to overcome monopoly profits. 
Lemma 2: The network effect expands the quantity more under duopoly than under monopoly.

Proof: $\frac{\partial q^{D}}{\partial n}=\frac{2 a}{[3-2(n+k)]^{2}} ; \frac{\partial q^{M}}{\partial n}=\frac{a}{(2-n-k)^{2}} ; \frac{\partial q^{D}}{\partial n}>\frac{\partial q^{M}}{\partial n}$.

Corollary. Although network effect always enhances the output expansion of duopoly more than monopoly, $q^{D}$ can be larger than $q^{M}$ if and only if firms are engaged in CSR activities.

Lemma 3: In the relevant parameter range, the network effect increases the price more under duopoly than under monopoly if $n \geq 1-\frac{\sqrt{2\left(2 k^{2}-3 k+1\right)}}{2}$.

Proof: $\frac{\partial p^{D}}{\partial n}=\frac{2 a(1-2 k)}{[3-2(n+k)]^{2}} ; \frac{\partial p^{M}}{\partial n}=\frac{a(1-k)}{(2-n-k)^{2}} ; \frac{\partial p^{D}}{\partial n} \geq \frac{\partial p^{M}}{\partial n} \Rightarrow n \geq 1-\frac{\sqrt{2\left(2 k^{2}-3 k+1\right)}}{2}$.

In other words, if the network effect is adequately intense, this moderates the fall in price due to output expansion to such an extent that, in duopoly, the price remains at a level sufficiently high to ensure the dominance of the quantity effect on profits. Taking into consideration Lemma 1 and 2, and the Corollary, the following total derivative allows for the analysis of the impact of the network effects on the monopoly/duopoly profit differential:

$$
\frac{\partial \pi^{M}}{\partial n}-\frac{\partial \pi^{D}}{\partial n}=\underbrace{-(1-n)\left(\frac{\partial q^{M}}{\partial n}-2 \frac{\partial q^{D}}{\partial n}\right)}_{>0}+\underbrace{p^{M} \frac{\partial q^{M}}{\partial n}}_{>0}-\underbrace{p^{D} \frac{\partial q^{D}}{\partial n}}_{>0} .
$$

However, it can be easily shown that

$$
\left.\lim _{n \rightarrow 1}\right|_{k \approx 0.5} p^{D}=0 ; \lim _{n \rightarrow 1} \frac{\partial q^{D}}{\partial \approx 0.5}=\infty,
$$

and the product $p^{D}\left(\partial q^{D} / \partial n\right)$ tends to infinity because $\partial q^{D} / \partial n$ tends to infinity at a speed higher than $p^{D}$ to zero. This implies that, for values of $k$ adequately high, there is always a level of the network effect sufficiently intense that makes the sign of the above total derivative negative.

Lemma 4: In the relevant parameter range, the social engagement has a complementarity effect on price only for sufficiently high level of the network externalities.

$$
\begin{aligned}
& \text { Proof: } \frac{\partial^{2} p^{D}}{\partial n \partial k}=\frac{4 a[1-2(n-k)]}{[3-2(n+k)]^{3}} \geq 0 \Rightarrow n \frac{\geq}{<}+\frac{1}{<}+k, \frac{\partial^{2} p^{M}}{\partial n \partial k}=\frac{a(n-k)}{(2-n-k)^{3}} \geq 0 \Rightarrow n \frac{\geq}{<} k, \\
& \frac{\partial^{2} p^{D}}{\partial n \partial k} \geq \frac{\partial^{2} p^{M}}{\partial n \partial k} \Rightarrow n \underset{<}{<} n^{T}(k),
\end{aligned}
$$

where the upper script $T$ stands for "threshold"10.

Lemma 4 may help to explain the hump-shaped effect of the CSR parameter, $k$, on the profit differential and the emergence of the profit raising effect when the network effects are sufficiently strong.

\footnotetext{
10 The analytical expression of $n^{\mathrm{T}}(k)$ is complex and not reported here for economy of space. However, it is available upon request from the authors
} 
The empirical implication is clear-cut: when network effects are strong, network industries in which firms adopt CSR rules should more often present a relatively more competitive structure than 1) the traditional goods industries; 2) network industries without CSR; and 3) network industries in which there is no universal adoption of CSR rules (one firm follows CSR while the rival does not). In fact, in those cases, the profit raising effect does not appear ${ }^{11}$.

Therefore, the antitrust and competition policies implication seems to be as follows: policy makers wishing to increase the competitiveness in network industries should incentivize the adoption of CSR rules in those sectors. However, an extremely cautionary note is here in order: those results are obtained under precise assumptions (quantity competition, marginal costs equal to zero, linear demand function, homogeneous goods, exogenous CSR parameter). A robustness check of those results under alternative configurations such as price competition, positive marginal costs under constant and decreasing return-to-scale technologies and heterogeneous goods is definitely called for. In fact, the current findings could be altered and, consequently, the policy insights.

\section{Conclusion}

This paper has investigated the presence of the profit raising effect in network industries in which firms follow Corporate Social Responsibility (CSR) behaviours.

The analysis reveals that when network effects are very intense, the presence of CSR rules, especially when the firms' social concern is neither very low nor very high, makes possible the emergence of the profit raising effect: the incumbent can invite an entrant. This result is at odds with the conventional wisdom and shows an additional channel, so far not explored by the preceding literature, for the possibility of a profit raising entry.

These findings contribute to the increasing policy debate on firms' social concern and has evident significance for antitrust and competition policies: potentially, to increase competitiveness, policy makers should incentivize the adoption of CSR rules in network industries.

The current model is based on a precise set of assumptions, and therefore several extensions are definitively called for to check the robustness of the findings. First, it would be appropriate to investigate the model in which the firms are able to commit on their output levels. Second, an analysis of different competition modes, notably price competition with differentiated products, is a further suitable direction of research. Finally, to introduce a manager to whom the sales and CSR level decisions are delegated can alter the current results. Those extensions are left for future research.

\section{References}

Ashiya, M. (2000) Weak Entrants are Welcome, International Journal of Industrial Organization, 18, 975-984.

Baron, D.P. (2001) Private Politics, Corporate Social Responsibility, and Integrated Strategy, Journal of Economics and Management Strategy, 10, 7-45.

Baron, D.P (2009) A Positive Theory of Moral Management, Social Pressure, and Corporate Social Performance, Journal of Economics and Management Strategy, 18, 7-43.

\footnotetext{
${ }^{11}$ In standard goods industries, in the presence of the common assumptions of the current model, it is a wellestablished result that the profit raising effect does not emerge. As regards network industries without CSR, see Buccella and Fanti (2016). The result related to the mixed behaviours in duopoly can be straightforwardly derived and omitted here for economy of space. However, analytical details are available upon request from the authors.
} 
Benabou, R. and Tirole, J. (2010) Individual and Corporate Social Responsibility, Economica, 77, 1-19.

Bhattacharjee, T. and Pal, R. (2013) Price vs. quantity in duopoly with strategic delegation: Role of network externalities, Indira Gandhi Institute of Development Research, working paper number IGIDR-WP-2013-003, Mumbai, India.

Bhattacharjee, T. and Pal, R. (2014) Network externalities and strategic managerial delegation in Cournot duopoly: Is there a prisoners dilemma?, Review of Network Economics, 12(4), 343-353.

Bennett, J., Iossa, E. and Legrenzi, G. (2003) The role of commercial non-profit organizations in the provision of public services, Oxford Review of Economic Policy, 19, 335-347.

Benz, M. (2005) Not for profit, but for satisfaction? Evidence on worker well-being in nonprofit firms, Kyklos, 58, 155-176.

Buccella, D. and Fanti, L. (2016) Entry in a Network Industry with a "Capacity-Then-Production" Choice, Seoul Journal of Economics, 29(3), 411-429.

Chen, Y. and Riordan, M.H. (2007) Price and Variety in the Spokes Model, Economic Journal 117, 897-921.

Chirco A., and Scrimitore M. (2013) Choosing price or quantity? The role of delegation and network externalities, Economics Letters, 121, 482-486.

Church, J. and Ware, R. (1999) Industrial Organization: A Strategic Approach, Irwin McGrawHill, Boston, MA.

Coughlan, A. T. and Soberman, D.A. (2005) Strategic Segmentation Using Outlet Malls. International Journal of Research in Marketing, 22, 61-86.

Donaldson, T. and Preston, L. (1995) The stakeholder theory of the corporation: Concepts, evidence, and implications, Academy of Management Review, 20, 65-91.

European Commission (2001) Promoting a European framework for corporate social responsibility, green Paper, Office for Official Publications of the European Communities, Luxembourg.

Fanti, L. and Buccella, D. (2016) Bargaining Agenda and Entry in a Unionised Model with Network Effects, Italian Economic Journal, 2(1), 91-121.

Fanti, L., and Buccella, D. (2017a) Manager-Union Bargaining Agenda Under Monopoly and with Network Effects, Managerial and Decision Economics, 38(6), 717-730.

Fanti, L., and Buccella, D. (2017b) The effects of corporate social responsibility on entry, Economia e Politica Industriale - Journal of Industrial and Business Economics, 44(2), 259-266.

Fanti, L., and Buccella, D. (2017c) Corporate Social Responsibility in a game theoretic context. Economia e Politica Industriale - Journal of Industrial and Business Economics, 44(3), 371-390.

Frank, R. (2003) What Price the Moral High Ground? Ethical Dilemmas in Competitive Environments, Princeton University Press, Princeton and Oxford.

Freeman, R.E. (1984) Strategic management: A stakeholder perspective, Englewood Cliffs, NJ: Prentice Hall.

Garriga, E. and Melè, D. (2004) Corporate Social Responsibility Theories: Mapping the Territory, Journal of Business Ethics, 53, 51-71.

Goering, G.E. (2007) The strategic use of managerial incentives in a non-profit firm mixed duopoly, Managerial and Decision Economics, 28, 83-91.

Goering, G.E. (2008) Welfare impacts of a non-profit firm in mixed commercial markets, Economic Systems, 32, 326-334.

Hoernig, S. (2012) Strategic delegation under price competition and network effects, Economics Letters, 117(2), 487-489. 
Ishibashi, I. and Matsushima, N. (2009) The Existence of Low-end Firms may Help High-end Firms, Marketing Science, 28, 136-147.

Ishida, J., Matsumura, T. and Matsushima, N. (2011) Market Competition, R\&D and Firm Profits in Asymmetric Oligopoly, Journal of Industrial Economics, 59, 484-505.

Jensen, M.C. (2001) Value maximization, stakeholder theory, and the corporate objective function, Journal of Applied Corporation Finance, 14(3), 8-21.

Katsoulakos, P., Sapouna, T. and Zevgolis, D. (2004) CSR Classification and Corporate Sustainability Indicators, CSRQuest Sustainability Framework White Paper CA1B, available online at http://www.csrquest.net/uploadfiles/1B.pdf.

Katz, M. and Shapiro, C. (1985) Network externalities, competition, and compatibility, American Economic Review, 75(3), 424-440.

KPMG (2013) KPMG Survey of Corporate responsibility reporting 2013, available online at https://assets.kpmg.com/content/dam/kpmg/pdf/2015/08/kpmg-survey-of-corporate-responsibility-reporting-2013.pdf.

Lambertini, L. and Tampieri, A. (2010) Corporate Social Responsibility in a Mixed Oligopoly, Department of Economics, University of Bologna, working paper 723.

McAfee, R.P., Mialon, H.M., and Williams, M.A. (2003) Economic and Antitrust Barriers to Entry, Mimeograph, available at http://vita.mcafee.cc/PDF/Barriers2Entry.pdf.

McAfee, R.P., Mialon, H.M., and Williams, M.A. (2004) What is a barrier to entry?, American Economic Review, 94, 461-465.

McWilliams A., Siegel D.S., and Wright, P.M. (2005) Corporate Social Responsibility: Strategic Implications, Rensselaer Working Papers in Economics, n. 0506, May.

Mukherjee, A., Broll, U. and Mukherjee, S. (2009) The Welfare Effects of Entry: the Role of the Input Market, Journal of Economics, 98, 189-201.

Mukherjee, A. and Zhao, L. (2009) Profit Raising Entry, Journal of Industrial Economics, 57(4), 870-870.

Nakamura, Y. (2013) Social welfare under quantity competition and price competition in a mixed duopoly with network effects: An analysis, Theoretical Economics Letters, 3(4), 211-215.

Naylor, R. A. (2002a) Industry Profits and Competition under Bilateral Oligopoly, Economics Letters, 77, 169-175.

Naylor, R. A. (2002b) The effects of entry in bilateral oligopoly, Mimeo. University of Warwick.

Pal, D. and Sarkar, J. (2001) A Stackelberg Oligopoly with Non-identical Firms, Bulletin of Economic Research, 53, 127-134.

Planer-Friedrich, L. and Sahm, M. (2016) Strategic Corporate Social Responsibility, Mimeo, University of Bamberg.

Reputation Institute (2015) 2015 Global CSR RepTrak 100, available online at http://www.reputationinstitute.com/CMSPages/GetAzureFile.aspx?path= \medialmedialdocuments 12 015-global-csr-reptrak-results.pdf\&hash=f375854351576541ae88db1e043e74 17e9f05 7f83955bb3768454dd8e0417353\&ext=.pdf.

Schiff, J., and Weisbrod, B. (1991) Competition between for-profit and non-profit organizations in commercial markets, Annals of Public and Cooperative Economics, 62, 619-639.

Spitzeck, H., and Hansen, E.G. (2010) Stakeholder governance: how stakeholders influence corporate decision making, Corporate Governance: The International Journal of Business in Society, 10(4), 378-391.

Tyagi, R. (1999) On the Effects of Downstream Entry, Management Science, 45, 59-73. 